\title{
JUDICIALIZAÇÃO DA SAÚDE E SEUS REFLEXOS NA GESTÃO DO SISTEMA ÚNICO DE SAÚDE (SUS).
}

\author{
Carlos Eduardo Artiaga Paula ${ }^{1}$ \\ Cléria Maria Lôbo Bittar ${ }^{2}$
}

\section{RESUMO:}

O estudo visa identificar as críticas à judicialização da saúde e seus reflexos na gestão do Sistema Único de Saúde (SUS) por meio de uma revisão literária. Identificou-se seis críticas: (1) a judicialização impede o planejamento do SUS; (2) o Judiciário é dotado de falhas estruturais; (3) não é sua função criar políticas; (4) a responsabilidade solidária dos entes federativos desestrutura o SUS; (5) o Judiciário é manipulado por elites econômicas; (6) a judicialização desconsidera os limites econômicos. Concluiu-se que, apesar das críticas, o Judiciário tem um relevante função e deve, com o Executivo e Legislativo, desenvolver acordos para efetivar a saúde.

Palavras-chave: Judicialização - Saúde - Gestão - Sistema Único de Saúde - Crítica.

\section{JUDICIALIZATION OF HEALTH AND ITS REFLEXES IN THE MANAGEMENT OF THE SISTEMA ÚNICO DE SAÚDE (SUS).}

\begin{abstract}
:
The study aims to identify the critiques of the judicialization of health and its reflexes in the management of the Sistema Único de Saúde (SUS) through a literary review. Six criticisms were identified: (1) the judicialization prevents SUS' scheming; (2) the Judiciary is endowed with structural failures; (3) it isn'ttheir function to create policies; (4) the joint responsibility of federal entities disorganize SUS; (5) the Judiciary is manipulated by economical elites; (6) the judicialization disregards budget limits. It was concluded that, despite the criticisms, the Judiciary has a relevant function and should, with the Executive and the Legislative, develop agreements to effect health.
\end{abstract}

Keywords: Judicialization - Health - Management - Sistema Único de Saúde - criticismo.

\section{Introdução.}

A judicialização da saúde no Brasil é um fenômeno em crescente expansão. O relatório "justiça pesquisa” elaborado pelo Conselho Nacional de Justiça concluiu que há uma crescente busca pelo Judiciário (CONSELHO NACIONAL DE JUSTIÇA, 2015), que,

\footnotetext{
${ }^{1}$ Graduado e mestre em direito pela Universidade Federal de Uberlândia. Especialista em direito processual civil. Docente da Universidade Federal de Viçosa. Doutorando em promoção da saúde pela Universidade de Franca.

${ }^{2}$ Graduada em psicologia e direito pela Universidade de Franca. Mestre e doutora em serviço social pela Universidade Estadual Paulista. Docente permanente do Programa de Mestrado e Doutorado em Promoção da Saúde e do curso de Psicologia da Universidade de Franca.
} 
atualmente, importa em 300 mil ações (LAGUNA e CAMPOS, 2016).Diante do crescente aumento de ações judiciais, o meio acadêmico também demonstra preocupações com a questão e, por isso, a temática da judicialização da saúde também está crescimento (OLIVEIRA et. al., 2015; ARAÚJO et. al., 2013 e BOUSQUAT e TANAKA, 2016).

Embora seja um tema crescente, a interferência do Judiciário no Sistema de Saúde tem enfrentado inúmeros problemas e, com isso, é alvo de severas críticas. A partir dessa constatação é que advém o objetivo deste estudo que, a partir de uma revisão críticada literatura, visa identificar as principais argumentos contrários ao fenômeno da judicialização da saúde e seus reflexos na gestão do Sistema Único de Saúde (SUS). Este objetivo pode ser convertido na seguinte questão norteadora: com uma perspectiva crítica, quais os principais problemas que a judicialização da saúde acarreta para a gestão do SUS? A presente revisão literária observou as etapas metodológicas descritas por Moreira (2004), quais sejam: 1) escolha do assunto e estabelecimento dos objetivos; 2) levantamento bibliográfico; 3) leitura inspecional; 4) estabelecimento e aplicação do roteiro de leitura; 5) organização das pesquisas relevantes segundo critério lógico; 6) avaliação crítica; 7) conclusão.

Inicialmente, foram definidos o objetivo e a questão norteadora, conforme já mencionado. Em segundo lugar, foram pesquisados, no período de março a maio 2017, estudos, sobretudo artigos científicos, em diversas bases de dados na internet, notadamente as seguinte: o SCIELO - ScientificElectronic Library Online, a Biblioteca Virtual em Saúde, o Pubmed, o googleacadêmico e o Web of Science. Para o desenvolvimento da pesquisa, foram utilizadas as palavras-chave judicialização, saúde e gestão. Também foram empregados sinônimos, tais como: intervenção judicial, administração, governança entre outros. Nas buscas, as palavras-chave foram em língua portuguesa combinadas pelo operador lógico de pesquisa "and".

$\mathrm{Na}$ terceira etapa metodológica, que foi a leitura inspecional, foram selecionados artigos que atendiam aos objetivos e à questão norteadora da pesquisa, quais sejam, estudos que apontavam as críticas ao fenômeno da judicialização da saúde e sua repercussão para a gestão do SUS. Foram, então, selecionados os 25 principais estudos, citados nas referências, que, na óptica dos autores, tratavam desse assunto com maior profundidade. Foi, portanto, coletada um amostra de conveniência, pois não foi possível nem é pretensão desse estudo esgotar todos as publicações sobre a judicialização da saúde, já que há inúmeras sobre a temática. O recorte temporal foi o período de 1988 até a presente data, já que aquele ano foi o 
da promulgação da Constituição Federal $(\mathrm{CF})$ que consagrou, de forma ampla, o direito à saúde.

A quarta etapa consistiu em uma leitura minuciosa e fichamento dos textos escolhidos. $\mathrm{Na}$ quinta etapa, após o conhecimento profundo dos textos escolhidos, foi possível organizar as críticas quanto à interferência judicial no SUS em seis tópicos, que corresponde aos capítulos do presente estudo.A partir dessa organização, foi possível, também na sexta etapa, utilizar-se do recurso da comparação em que foi identificada e agrupada as discordâncias e semelhanças entre as várias considerações, agrupando-os nas seis categorias de análises, descritas na etapa metodológica anterior. Nessa fase, foi incluído, na discussão, outros estudos, dos quais se possuía conhecimento prévio, como Barroso (2009) eDworkin (2003)e também a documentos oficiais, como Banco Mundial (2007).

$\mathrm{Na}$ derradeira etapa metodológica, a conclusão, foram realizadas considerações críticas sobre cada um dos seis argumentos que apontam aspectos negativos da judicialização da saúde. Essa considerações também foram fundamentadas na literatura, no sentido trazer os benefícios da intervenção judicial no SUS. Ao final do trabalho, nas considerações finais, foi possível tecer conclusões acerca da judicialização da saúde, se este deve ser um fenômeno combatido, eliminado ou mantido.

\section{1) Primeira Crítica: a judicialização interfere negativamente no planejamento, igualdade e universalidade do SUS.}

A primeira tese crítica, encontrada em vários textos, foi a de que a judicialização da saúde impede um amplo planejamento financeiro por parte do estado, favorecendo a aquisição de medicamentos de alto custo, pois são adquiridos em caráter de urgência, sem licitação (DINIZ et. al., 2012; VENTURA et. al., 2010; MATTA e MARQUES, 2014; SANTOS, 2017; PEPE et. al., 2010). Isso interfere na consagração do princípio da universalização do SUS e também no da igualdade de atendimento, pois impede o Estado de atender de forma homogênea o máximo de pessoas possível.

A judicialização acarreta problemas financeiros para o Estado, pois os medicamentos adquiridos por determinação judicial, ou seja, em caráter de urgência, possuem um preço muito maior do que costumeiramente seria adquirido. Diniz et. al. concluíram que"se as compras fossem realizadas pela média dos cinco menores preços já pagos pelo ministério [...], 
haveria uma economia de R\$ 84 milhões nos cinco anos de judicialização" (DINIZ et. al, 2012, p. 487). Pepe et. al. (2010)esclarecem que "praticamente todos"os pedidos são deferidos em caráter liminar e, por isso, o medicamento deve ser entregue imediatamente. Isso acarreta problemas financeiros, além da adoção de "procedimentos de compra não usuais na administração pública" (PEPE et. al., 2010, p. 2406). Também não se pode esquecer dos problemas de gestão, pois o ente federativo deve ao mesmo tempo atender a essa demanda e as outras originárias do Sistema de Saúde.

Ventura et. al. (2010), bem como Matta e Marques (2014), por sua vez, enfatizam os prejuízos que a judicialização acarreta para um planejamento estatal adequado, necessário à consagração do direito à saúde, pois as decisões judiciais são atomizadas. Wang et. al. (2014) reforçam a ideia afirmando que a judicialização gera um grau de incerteza para o gestor público sobre ao quanto gastar, o que afeta o planejamento.Santos (2017), por sua vez, afirma que a as decisões judiciais desestruturam a organização do SUS e, com isso, a igualdade no fornecimento dos serviços de saúde, pois muitos usam a via jurisdicional para "furar a fila", não observando a ordem de atendimento.Ferraz e Vieira (2009), por sua vez, endossam o posicionamento de que a judicialização da saúde é caracterizada por demandas individuais com alta chance de sucesso em que o Judiciário, independentemente do custo, confere à parte o mais avançado tratamento em saúde disponível. Isso, evidentemente, afeta o princípio da universalidade e da isonomia, pois, considerando que os recursos econômicos são limitados, não é possível fornecer a todos o melhor tratamento para o combate de determinada doença.

Apesar de bem fundamentada a crítica de que a judicialização da saúde interfere no planejamento, na isonomia e na universalidade do SUS, também observou-se, na literatura, rejeições a essasassertivas. Quanto ao planejamento, a judicialização, por já repetir-se há anos, é um fenômeno previsível, quantificável e, por isso, possível de ser planejado.Consoante afirmam Ferraz e Vieira (2009), a judicialização da saúde iniciou na década de 90 e, por isso, já é possível conhecer, inclusive estatisticamente, a repercussão financeira da interferência judicial e, com isso,incluí-la no orçamento tanto que há, no Estado de Minas Gerais, um orçamento específico para as demandas judiciais (DEPOIMENTO..., 2013). A judicialização tanto é previsível quanto planejável. O Estado de São Paulo, por exemplo, promove "licitações preventivas" para a aquisição de medicamentos fornecidos mediante determinação judicial. Logo, observou-se que, naquele Estado, apenas 17,9\% do gasto da Secretaria Municipal de Saúde paracumprir decisões judiciais em 2011 foram 
adquiridos sem licitação.Wang et. al. (2014), contudo, entendem que as "licitações preventivas" geram o acesso desigual ao SUS, pois há os produtos licitáveis, acessíveis apenas àqueles que recorrem à via judicial. Contudo, é possível que esse medicamento esteja disponível a todos, basta o interesse político e o planejamento para fazê-lo.

Observa-se, portanto, que a judicialização da saúde é um fator a ser gerido pelo administrador público, como tantos outros que devem ser por ele considerados, tais como a escassez de recurso, as diversas, amplas e distintas demandas da população, a logística de acesso dos bens de saúde etc. Por isso que Oliveira e Noronha (2011) afirmam categoricamente que não basta analisar a judicialização em si, mas como o gestor reage a ela. Logo, acusar o Judiciário de impedir o planejamento do SUS indica uma dentre tantas outras falhas de gestão, visíveis no Sistema de Saúde brasileiro.

Quanto à universalidade e isonomia do SUS, observou-se no pensamento de Oliveira e Noronha (2011) que a judicialização não privilegia apenas a classe dos demandantes, pois a ingerência judicial impulsiona a criação de políticas públicas que beneficiam a todos. Um forte exemplo foram as políticas de combate à AIDS, conforme expõem Messeder et. al. (2005) e Scheffer et. al. (2005). As sucessivas e recorrentes ações judiciais impulsionaram não apenas o acesso aos medicamentos, mas também toda uma política pública ampla, madura e permanente de combate à AIDS. Em outras palavras, demandas judiciais repetitivas que condenam o Poder Público a fornecer determinado medicamento gera um indicativo de que esse fármaco precisa ser disponibilizado pelo SUS.

\section{2) Segunda Crítica: As falhas estruturais do Judiciário, como a ineficiência, morosidade e erros, impedem esse Poder de conceder um adequado acesso à saúde.}

A segunda tese, apontada nesse estudo, de crítica à judicialização da saúde, é que o Poder Judiciário é dotado de falhas graves que lhe impedem de garantir o direito à saúde, como a ineficiência, morosidade, elitização, além de incorrer com frequência em erros. Pinheiro (1999, p. 11) afirma que o Judiciário apresenta carências de recursos humanos, procedimentos extremamente burocráticos, juízes mal capacitados e sobrecarregados de trabalhos.Roberto A. R. de Aguiar (1990) observa que o direito, aplicado pelo Judiciário, não gera um igualdade real ou efetiva. Ao contrário, ele é conservador na medida em que proporciona uma estabilidade social, ou seja, trata-se de um instrumento de implantação e continuidade de uma dada ordem social. Logo, a atuação do Judiciário não está isenta da 
desigualdade social capitalista em que há a opressão de uma classe pobre por outra economicamente abastada.

Santos (2017, p. 11) compactua com essa tese ao afirmar que o Judiciário é incapaz de "estancar ou filtrar as demandas judiciais justas daquelas de caráter duvidoso ou improcedentes". O secretário do Estado de Minas Gerais,Antônio Jorge de Souza Marques, que exerceu sua função no período de 2010 a 2014, em entrevista disponibilizada pelo cursoa distância de judicialização da saúde em atenção domiciliar, promovido pela Universidade do Estado do Rio de Janeiro - UERJ (DEPOIMENTO..., 2013), afirmou que a judicialização já foi utilizada para o fornecimento de spa e coxinhas, o que desorganiza o SUS. Há, segundo o Secretário, muitos pedidos deferidos sem "substância técnica".

A morosidade judicial foi um grande problema apontado no relatório desenvolvido pelo Banco Mundial (2007) para a melhoria da governança do SUS. O referido estudo apontou o Judiciário como um problema, pois a interferência judicial em uma licitação de aquisição de um medicamento, por exemplo, pode paralisar o processo de compra durante meses ou até anos. Trata-se, portanto, da morosidade judicial interferindo na gestão do SUS.

O Judiciário também é elitista. Logo, embora a saúde seja um direito universal, o acesso à justiça não o é. Pepe et. al. (2010) observaram que as ações judiciais, em sua gritante maioria, são propostas individualmente. Logo, o resultado de uma ação não é estendido às demais pessoas que se encontram nas mesmas condições. Quem litiga, portanto, possui um rol muito mais amplo de ações e serviços de saúde, enquanto o restante da população tem acesso apenas ao que é definido nas políticas (WANG et. al., 2014; MESSEDER et. al. (2005), VIEIRA e ZUCCHI, 2007;CHIEFFI e BARATA, 2009).

Ao observar essa terceira crítica, não se pode negar que o Judiciário possui diversas deficiências, mas os Poderes Executivo e Legislativo também são suscetíveis a falhas as quais são facilmente constatadas a partir da forte desigualdade social, corrupção e má gestão dos recursos públicos que assola o Brasil. Essas conclusões também se aplicam ao SUS. Levantamento realizado pelo Ministério da Saúde que avaliou o Sistema Único de Saúde em 5,5 numa escala de 0 (pior) a 10 (melhor) (SAÚDE..., 2015). "Dados do Tribunal de Contas da União (TCU) indicam que 64\% dos hospitais estão sempre com superlotação. Apenas 6\% nunca estão cheios" (SAÚDE..., 2015). Faltam trabalhadores na área de saúde, sobretudo médicos, principalmente no interior. Também se constata a ausência de capacitação desses profissionais e a falta qualificação. 
Um forte fator que contribui pelos baixos índices de saúde são a próprias falhas de gestão do SUS. Oliveira et. al. (2015) e Freitas Filho e Sant'ana (2016) constataram que há uma elevada burocratização do sistema, muitas demandas e demoras na prestação de serviços. Recursos farmacêuticos, por exemplo, são mal geridos. Diniz et. al. (2012) em estudo realizado com 597 municípios (que corresponde a 10,7\% dos municípios brasileiros), observaram que $71 \%$ apresentaram controle de estoque ausente ou deficiente e em $39 \%$ deles foram observados condições inadequadas de armazenamento, o que demonstra falhas graves de gestão.

A partir dessas deficiências do SUS, visa-se, nesse estudo, questionar a crítica que se faz ao fenômeno da judicialização à saúde como se este fosse o principal problema da saúde pública e parece-nos que não é. Os elevados números de ações judiciais são, obviamente, um desafio a se enfrentar, mas há outras, principalmente as administrativas e financeiras, que impactam muito mais nos índices de qualidade do SUS.

Ademais, focar na judicialização como "problema" faz esquecer que a fonte das ações judiciais são as deficiências do próprio Poder Público, já que o Judiciário intervém diante da existência de uma lesão ou ameaça de lesão a direito, nos termos do art. $5^{\circ}$, inc. XXXV da Constituição Federal (CF). O cerne, portanto, das ações judiciais são as falhas do SUS e, como estas são graves e frequentes, não é de se espantar que haja uma forte judicialização.

Ademais, se for considerado o ponto de vista apenas do Poder Público, há fortes chances de se concluir que a judicialização da saúde é um problema. Contudo, se considerarmos o cidadão, este desejará ter garantido o acesso à justiça, sobretudo, quando o Poder Público recusar-se a lhe deferir um pedido. O Judiciário nesse caso será uma outra instância, legal e legítima, que a pessoa pode utilizar-se para fazer valer os seus direitos. Ainda, se forem considerados os fortes problemas que assolam o SUS, concluir-se-á que a instância judicial não é apenas desejável, mas necessária para que alguns cidadãos tenham acesso à saúde, sobretudo grupos minoritários.

Observa-se, ainda, a partir da leitura da obra de Dworkin (2003), que o Judiciário também é uma instância relevante por fazer uma leitura moral dos direitos e dos valores caros à sociedade, como à saúde. Logo, as decisões judiciais são dotadas de uma flexibilidade e possibilidade de modificação que não se observa no Poder Público que, na grande maioria dos casos, aplica rigidamente o que preveem as normas jurídicas com uma perspectiva pragmática, já que considera os recursos econômicos disponíveis. Essa visão moral do 
Judiciário permitiu grandes avanços na consagração dos direitos fundamentais, como o reconhecimento da união homossexual (BRASIL, 2011) e, no sistema de saúde, autorizou o uso da cannabisque, comprovadamente, fazia diminuir as crises epilépticas de uma criança, embora esta seja uma substância, cujo uso é considerado crime (OLIVEIRA, 2014). Essa visão é reforçada também diante da constatação que, em um sistema desigual e corrupto, nem sempre as decisões políticas são tomadas de forma racional em benefício da maioria, mas em prol de minorias detentoras do poder econômico e político ou para àquelas demandas sociais que rendem mais votos (OLIVEIRA e NORONHA, 2011).

Os próprios gestores públicos reconhecem algumas demandas judiciais como legítimas.Ribeiro (2014) aponta que os próprios gestores orientam o cidadão a propor uma ação judicial, buscando o acesso ao medicamento que ele, na condição de administrador, não pode conceder, sob pena de até ser responsabilizado. Na visão da autora, orientar a pessoa sobre o direito de acesso à justiça também é uma função a ser desempenhada pelos assistentes sociais.

Outra crítica que se faz ao Judiciário é a morosidade, que, todavia, pode ser positiva para a gestão do SUS, pois o cidadão antes de enfrentar um longo e moroso processo judicial buscará o competente órgão de saúde para tentar resolver a questão. As causas da lentidão na prestação jurisdicional são diversas, mas o relatório elaborado pelo Conselho Nacional de Justiça (CNJ) (2011a, p. 32), intitulado "Demandas repetitivas e a morosidade na Justiça cível brasileira"trouxe a conclusão de que vários atores, em destaque, o "governo", fomentam o crescimento da litiosidade. Associado a esse dado, temos a constatação do desembargador do Tribunal de Justiça de São Paulo, José Renato Nalini, o qual afirma que "a morosidade da justiça só serve quem não tem razão" (SCOCUGLIA, 2014). Tais conclusões, associada ao fato de que o Poder Público é o maior litigante no Brasil, responsável por 39,26\% (trinta e nove vírgula vinte e seis por cento) das ações judiciais, conforme dados do CNJ (2011), levanos a questionar se há, realmente, interesse político em uma Justiça célere no Brasil ou se o Estado e/ ou grupos econômicos que souberam lucrar com a morosidade impõe a manutenção dessa condição.

Quanto à crítica de que o Judiciário é acessível apenas para quem tem renda elevada, esta é refutada por Oliveira e Noronha (2011). Segundo os autores, a renda da pessoa não é um fator considerado nas ações judiciais e, ademais, há advocacia pública e gratuita para quem a procurar.Até o SUS disponibiliza o acesso à saúde para todos (princípio da 
universalidade) e não apenas para quem tem condições financeiras avantajadas. Ademais, há pessoas que podem ser consideradas financeiramente abastadas, mas que não consigam custear o seu tratamento de saúde, dada a existência de tratamentos com elevado custo, inacessíveis para grande parte da população. Oliveira e Noronha (2011) citaram o exemplo de um tratamento que custe $\mathrm{R} \$ 20000,00$ por mês para uma pessoa, cuja renda familiar é de $\mathrm{R} \$$ 12000,00 por mês. Logo, o acesso à saúde pública faz-se necessário.

Por fim, quanto à possibilidade de erro nas decisões judiciais, estas sempre existirão, o que não desvirtua a relevância da intervenção judicial. É necessário, contudo, tomar-se providências para minimizá-los, medidas estas que já se observa no Judiciário. O Supremo Tribunal Federal (STF) em decisão judicial (BRASIL, 2010a), estabeleceu parâmetros para orientar os magistrados ao apreciar as ações judiciais de saúde. O Conselho Nacional de Justiça (2010), por sua vez, por meio da Recomendação n. ${ }^{\circ}$ 31, também estabeleceu critérios para uma adequada decisão judicial na área de saúde. O próprio Executivo e Legislativo, que culpam o Judiciário dos problemas da judicialização da saúde, possuem a prerrogativa de editar leis, determinando, por exemplo, um procedimento especial a ser observado nas ações que envolvessem os serviços de saúde do SUS, além de terem a função institucionalde municiar os magistrados de recursos para uma adequada tomada de decisão, como, por exemplo, estabelecer um médico-perito judicial que atuasse como um assessor permanente do Juiz para analisar as ações envolvendo o SUS. Logo, o próprio Poder Político possui os meios legais e institucionais disponíveis para lidar com a questão da judicialização.

\section{3) Terceira crítica: O Judiciário interfere indevidamente nas políticas públicas e seus membros não possuem respaldo democrático.}

Uma terceira crítica que se faz à interferência do Judiciário no SUS é que não é função desse Poder gerir os recursos, criar ou aplicar as políticas públicas, até porque os membros do Judiciário, notadamente os magistrados, não são eleitos democraticamente pela população.

É fato que não são atribuições do Judiciário, previstas na Constituição, criar e aplicar as políticas públicas para gerir o sistema de saúde. Contudo, observa-se que o Judiciário, no exercício de suas funções constitucionais, exerce, atipicamente, a função de gestor público. Nesse sentido, Pepe et. al. (2010) apontam que, quando o Judiciário interfere no SUS e determina o fornecimento de um medicamento que não consta no SUS, ele compele o Poder 
Público a incluir o fármaco em sua lista oficial. O Judiciário então força a Administração a priorizar certos medicamentos, impondo, assim, uma determinada forma de gestão pública. Em outras palavras, o Judiciário avoca para si a função de administrador, determinando a aquisição de determinados bem de saúde. Também em consonância com esse entendimento, Wang et. al. (2014, p. 1200) afirmam que "uma parcela significativa dos recursos da políticade assistência farmacêutica e de distribuição de outros materiais em saúde está sendodeterminada e realocada judicialmente".

Deste fato, advém o grave problema de que o Judiciário não é um Poder preparado para administrar, pois as decisões judiciais consideram situações singulares e o Juiz não possui uma visão abrangente sobre aquele departamento de saúde. O magistrado não conhece os recursos financeiros de que dispõe o setor, não conhece o público que precisa ser atendido e também não avalia as repercussões financeiras e políticas daquela decisão. Ao interferir na gestão do SUS, o Judiciárioaltera o planejamento do setor de saúde, prejudicando "a garantia da disponibilidade dos medicamentos nas quantidades adequadas e no tempo oportuno, para atender às necessidade da população" (PEPE et. al., 2010, p. 2408).

A falta de respaldo democrático é outra árdua crítica que se faz ao Judiciário, pois os Juízes, que não são eleitos democraticamente pela população, ao interpretar e aplicar as leis, inovam no ordenamento jurídico, principalmente quando se baseiam nos princípios que são gerais (WOLKMER, 2003).Outro problema é a interferência do Judiciário em questões políticas, o que se chama de ativismo judicial, sem, contudo, terem respaldo democrático, o que ocorreu diversas vezes no Brasil e também nos Estados Unidos. Waldron (2010) afirma que incumbir a um grupo seleto de pessoas a tarefa de decidir os valores democráticos mais relevantes implicaria em violar a democracia, retirando dos cidadãos a oportunidade de decidirem sua própria vida.

O que se observa de contra-argumento a essa terceira corrente é que existe um forte abismo entre as promessas, contidas na lei, e o que, de fato, é aplicado na realidade. Nesses vazios, o Judiciário, muitas vezes, é convocado para intervir. E, quando o faz, tem como fundamento as leis que são democraticamente criadas pelo Poder Público e, por isso, contribui para conferir efetividade aos atos normativos.

O Judiciário também interfere quando os demais Poderes - Legislativo e Executivo demonstram-se inertes ou ineficientes. Isso ocorreu na regulamentação do direito de greve dos servidores públicos, que, apesar de previsto no art. 37, inc. VII da CF, não houve, até a 
presente data, a criação de um lei regulamentando esse direito. Logo, o Supremo Tribunal Federal entendeu legítimo o exercício desse direito e estendeu a aplicação da lei de greve da iniciativa privada (Lei 7.783/89) aos servidores públicos (CONCEIÇÃO, 2008). A omissão do Poder Político também é observada na ausência de regulamentação da união homossexual que foi possível a partir da intervenção judicial (BRASIL, 2011). No âmbito do SUS, o Judiciáriocontribuiu fortemente para a criação da política de combate à AIDS, conforma já mencionado.

Observa-se, então, que o Legislativo e Executivo não regulamentam vários direitos por falta de vontade política ou pelo“custo político" de decidir, que pode ser contrário à opinião pública e acarretar, consequentemente, a perda de votos (conforme ocorreu no reconhecimento da relação homoafetiva como unidade familiar). Por outro lado, o Judiciário precisa resolver os litígios que lhe são submetidos, ou seja, dar resolubilidade às questões. Em algumas situações, contudo, dar uma resposta implica em interferir nas funções dos demais poderes. Essa situação, por si só, não pode ser considerada negativa, pois o sistema de repartição dos poderes, em sua origem, previu a essa interrelação e interferências recíprocas a partir do sistema do "checksand balances" (BARROSO, 2009).A falta de respaldo democrático é um argumento também combatido na literatura, pois as atribuições do Judiciário são previstas em leis, criadas democraticamente. Ademais, as decisões judiciais não são imutáveis, pois, caso o Legislador não coadune com o entendimento jurisprudencial, pode modificá-lo, criando-se uma lei em sentido contrário ao entendimento dos tribunais.

\section{4) Quarta crítica: a judicialização da saúde, ao estabelecer a responsabilidade solidária dos entes da federação nas ações de saúde, desorganiza o SUS.}

O quarto argumento crítico, apontado nesse estudo, é que a judicialização da Saúde, ao estabelecer a responsabilidade solidária de todos os entes da federação (BRASIL, 2015), desorganiza e desestrutura do SUS, onerando sobremaneira os Municípios, cujos recursos financeiros são inferiores, quando comparados aos do Estados e da União.

Wang et. al. (2014) explicam que o SUS, no que tange ao fornecimento de medicamentos, se organiza, federativamente, da seguinte forma: os municípios são responsáveis pela assistência farmacêutica básica, os estados e a União pelos medicamentos especializados e esta última pelo fornecimento dos medicamentos estratégicos. Logo, 
preocupou-se em atribuir as ações de saúde mais onerosas e que demandam mais infraestrutura para os entes com maior capacidade de provê-las, ou seja, os Estados e a União. A intervenção judicial no SUS, todavia, inverte essa lógica, pois a maior parte do gasto da judicialização do Município de São Paulo, por exemplo, é direcionada para a aquisição de medicamentos e insumos cujo fornecimento sãoda competência de outro ente. Logo, a judicialização onera excessivamente os municípios, que são os entes federados, a rigor, mais pobres. Por conseguinte, poucos ou até uma única ação pode comprometer os recursos desses entes.

Por sua vez, Santos (2017) explica que as demandas, quando propostas contra qualquer ente da federação, desconsidera que eles se diferemsocioeconômica, demográfica e epidemiológicamente. Sem considerar que desorganiza a distribuição de competências dos serviços no âmbito do SUS. Logo, a judicialização da saúde faz com que um ente, por determinação judicial, exerça funções que não eram de sua competência e não estavam planejadas entre os serviços que prestaria, entendimento este também compartilhado por Pepe et. al. (2010), os quais complementam afirmando que essa responsabilidade solidária redesenha a estrutura organizativa de assistência farmacêutica do SUS.

A referida crítica de que o Judiciário, ao determinar a responsabilidade solidária dos entes da federação, desorganiza e desestrutura o SUS, também apresenta falhas. Parece evidente, de um lado, que a repartição de competências organiza o Sistema de Saúde, mas de outro lado, o torna complexo e pode ser um empecilho para o cidadão alcançar o seu direito, fato este reconhecido por Wang et. al. (2014). É comum o cidadão, no exercício do seu direito à saúde, passar por diversos órgãos e autoridades que se esquivam de conceder o pedido, alegando que esta não é sua atribuição, sem que os departamentos cheguem a um consenso sobre quem deve atender à demanda de saúde (ESTEVAM et. al., 2011). Se considerarmos a perspectiva da pessoa, singularmente considerada, a burocracia estatal é como um teia ou labirinto de princípios, regras, decretos, resoluções etc., onde é muito fácil se perder. E, com isso, não se confere resolubilidade às demandas sociais (OLIVEIRA et. al. 2015). A burocracia pública facilita a organização do sistema, o que é uma forte virtude. Mas, muitas vezes, é ineficaz, pois priva o cidadão do seu direito e, pior, oculta a responsabilidade do servidor público que, culposamente, incorre em falhas.

O Judiciário, apesar de ser suscetível a diversas críticas, é uma instituição em que a população acredita que pode resolver a questão do acesso à saúde, fato este comprovado a 
partir do elevado número de ações judiciais propostas (CONSELHO NACIONAL DE JUSTIÇA, 2016). Ao determinar o acesso a um medicamento, o Judiciário tem a prerrogativa de impor condutas coercitivas ao Poder Público, como multas, bloqueio em contas bancárias públicas (BRASIL, 2010) e até responsabilizar, pessoalmente, a pessoa do gestor, caso a ordem não seja cumprida. Essas prerrogativas do Judiciário, pelo simples fato de existirem, proporcionam ao cidadão um sentimento de resolutividade, muito embora se reconheça que a morosidade é um empecilho para a efetivação da justiça.

Além disso, muitas demandas da saúde são urgentes e, por isso, requerem providências imediatas. Por isso, não é possíveldiscutir-se, de forma ampla, de quem é a competência para se conceder um medicamento, por exemplo. Esse é um dos fatores que ensejaram no entendimento jurisprudencial do STF que determina a responsabilidade solidária dos entes da federação para conceder bens de saúde (BRASIL, 2015). Ou seja, deve-se fornecer o remédio ao demandante e, somente depois, discutir-se qual esfera de governo arcará com esse custo. Logo, o Município de São Paulo, que arca com o custo de um medicamente de competência da União, tem o direito de requerer, judicialmente, que seja ressarcido pelo ente federal.

Também não se pode esquecer que a situação também pode ser resolvida por meio de uma postura política: mediante a criação de uma lei ou até uma emenda à Constituição, definindo de forma clara a competência do entes da federação no SUS e afastando a responsabilidade solidária até porque o Judiciário deve obediências às leis. Logo, parece-nos que a solução sobre como lidar com esse problema não foge da esfera do próprio Poder Público.

\section{5) Quinta crítica: O Judiciário pode ser usado para atender interesses de mercado e não anseios sociais.}

A quinta crítica que se faz à judicialização da saúde, apontada nesse estudo, é que o Judiciário é manipulável e pode ser usado para atender os anseios do mercado (notadamente das indústrias farmacêuticas) ao, por exemplo, deferir o pedido de acesso a determinado medicamento não previsto nas listas oficiais, sem regulamentação da ANVISA ou sem uma forte confirmação científica, o que onera sobremaneira o sistema e pode expor o paciente a risco (PEPE et. al., 2010). 
A afirmação de que a judicialização da saúde é usada por elites econômicas encontra amparo na pesquisa desenvolvida por Marques e Dallari (2007). Estes, ao analisarem decisões judiciais envolvendo o acesso a medicamentos ao Estado de São Paulo, concluíram que, em $35,5 \%$ dos pedidos, constavam o nome do laboratório farmacêutico e em 77,4\% dos casos requeriam um específico medicamento. Os litigantes não requeriam que as suas doenças fossem tratadas por um específico composto ou tipo de medicamento, mas queriam um determinado produto.

Essa tese é reforçada por Wang et. al. (2014) ao constatar que quem define a necessidade de um determinado medicamento não é o paciente e sim o médico, pois é este que emite os laudos nos quais o Juiz se baseará para decidir. Ocorre que estes profissionais da saúde encontram-se intimamente ligados às indústrias farmacêuticas que gastam bilhões de dólares para propagar seus novos e mais caros produtos, embora, muitos destes, não tragam, necessariamente, benefícios para os pacientes. Os médicos não prescrevem com base em um princípio ativo, mas fazem constar o nome do produto. Tal situação é catalisada com o fato de que muitos juízes determinam a entrega do produto sem, às vezes, ouvir o parecer do Poder Público. Os autores terminam suas considerações afirmando que, na judicialização da saúde, poucos médicos e firmas de advogados são responsáveis pela maioria dos litígios.

As empresas farmacêuticas também promovem ações judiciais para testarem seus tratamentos e remédios, pois muitas drogas, deferidas pelo Judiciário, não são certificadas pela ANVISA, conforme Vieira e Zucchi (2007) e Chieffi e Barata (2009). Isso significa que os órgãos responsáveis no Brasil ainda não haviamverificado se o medicamento era seguro e efetivo, o que pode causar riscos ao paciente, além de terem um custo maior.Outro grande reflexo da influência da indústria farmacêutica na judicialização do SUS é o impacto financeiro. Dados do Estado de São Paulo demonstram que um paciente, cujo tratamento foi patrocinado pelo Judiciário, custa $\mathrm{R} \$ 10.600$, enquanto outros custam, em média, $\mathrm{R} \$ 2.500,00$ (OLIVEIRA e NORONHA, 2011).

O Judiciário, ainda, por não dispor de conhecimento técnico na área de saúde comete frequentes equívocos nos julgamentos.Oliveira e Noronha (2011) apresentou um exemplo prático que, segundo os autores, ocorre repetidas vezes. Afirmaram que há ações judiciais requerendo um medicamento que contém, em um só capsula, 300mg do ácido acetilsalicílico. Ocorre que o SUS disponibiliza esse mesmo medicamento, mas com a dosagem de $100 \mathrm{mg}$. Ou seja, bastaria o paciente tomar 3 pílulas ao invés de uma. Em contrapartida, o deferimento 
desse pedido gera prejuízos ao Município, pois enquanto uma pílula de $100 \mathrm{mg}$ custa $\mathrm{R} \$ 0,01$ (pelo Programa Dose Certa), ou seja, R \$ 0,03 para atender à necessidade do paciente; a pílula de 300 mg custa $R \$ 0,71$, ou seja, 23 vezes o valor de $R \$ 0,03$. Os autores ainda ressaltam que adquirir medicamentos de uma mesma fórmula com dosagens diferentes onera o Poder Público não apenas no custo do medicamento, mas também no ônus administrativo para se fazer tal aquisição, já que envolve tempo e recursos humanos de um sistema burocrático e moroso, que visa conferir transparência e evitar a corrupção dos gastos públicos.

Essas constatações também são observadas no estudo de Vieira e Zucchi (2007)que analisaram 170 ações judiciais contra o Município de São Paulo e observaram que 62\% dos medicamentos requeridos estavam inclusos na lista de fármacos do SUS para a distribuição gratuita. Dos 38\% remanescentes, $73 \%$ poderiam ser facilmente substituídos por um medicamento similar, distribuído pelo SUS. Logo, é muito comum as pessoas requererem ao Judiciário medicamentos que lhes são mais convenientes, enquanto há outros medicamentos ou tratamentos, igualmente eficazes para o tratamento, que são disponibilizados pelo Sistema de Saúde (OLIVEIRA e NORONHA, 2011).

Esse posicionamento de que o Judiciário é usado por elites econômicas e pela indústria farmacêutica também precisa ser cautelosamente analisado.Um litigante, cuja doença não possui tratamento previsto no SUS, mas há outro com chances de êxito (e também de falhas), precisa do amparo do estado. Afinal, o acesso ao tratamento de saúde e medicamentos é acessível a todos, independentemente da condição financeira, já que é dever do Estado fornecer, de forma igual e universal, o direito à saúde. Essas minorias, cujos tratamentos de saúde não são disponibilizados pelo SUS, muitas vezes não possuem o amparo do Executivo, sobretudo quando o atendimento médico-hospitalar possui um elevado valor. Mas este grupo minoritário, em contrapartida, encontram, no Judiciário, o amparo de que necessitam (COUTO e OLIVEIRA, 2016). Foi isso que ocorreu com os portadores do vírus HIV que tiveram as suas demandas inicialmente rejeitadas pelo Executivo.

A visão do Judiciário como protetor das minorias marginalizadas encontra amparo no pensamento constitucional de Ronald Dworkin (2003). Segundo o Autor, o papel dos juízes e da Constituição é proteger "os indivíduos contra aquilo que a maioria considera correto" (DWORKIN, 2003, p. 299), que é feito a partir de uma leitura moral sobre os preceitos fundamentais de nossa Constituição. Segundo o Autor, a dimensão política pode fazer perder o aspectohumano, pois visa administrar os recursos, que são escassos, para o maior número de 
pessoas possíveis, o que pode gerar prejuízos às minorias. Um outro exemplo da interferência judicial para assegurar os direitos de minorias foi a discussão acerca do direito à cirurgia de transgenitalização dos transexuais que foi assegurado mediante a intervenção judicial (BRASIL, 2007a).

Quanto à alegação de que o Judiciário é manipulado por elites econômicas, em especial às indústrias farmacêuticas, esta crítica é aplicada não apenas ao Judiciário, mas a todo o Poder Público brasileiro, caracterizado por forte corrupção, escândalos políticos, fraudes em processos de licitação, "mensalão", lobbies entre outros. As insuficiências do Judiciário em não conseguir obter uma adequada orientação técnica para proferir um julgamento também pode ter seus efeitos minimizados por atos do Executivo e Legislativo, editando leis, prevendo procedimentos específicos para a judicialização da saúde ou contratando servidores públicos com formação em medicina para atuar como peritos técnicos, conforme já mencionado.

\section{6) Sexta crítica: O Judiciário desconsidera, nas suas decisões, o princípio da reserva do possível.}

Por fim, o último argumento crítico à judicialização à saúde, apontada nesse trabalho, refere-se ao chamado princípio da reserva do possível, segundo o qual oPoder Público não confere melhores condições de saúde por falta de recursos e porque o Estado não tem condições de fornecer a todos o melhor tratamento. $\mathrm{Na}$ óptica das autoridades governamentais, na área de saúde, as pessoas esperam mais do que o Poder Público tem condições de fornecer (DEPOIMENTO..., 2013).

É fato que os recursos são escassos e os anseios sociais são infinitos. Mas o discurso da falta de recursos, conforme estabelece Ribeiro (2014, p. 148), pode não significar, efetivamente, a inexistência de condições financeiras, mas "uma opção política do Estado em priorizar os seus interesses, em detrimento da materialização dos direitos formais”. Logo, o Judiciário ao determinar a concessão de um benefício de saúde força o Executivo a cumprir a lei, notadamente o art. $6^{\circ}$, que determina ser a saúde um direito da pessoa.

O Judiciário parte do pressuposto que as leis são criadas por representantes do povo por meio de um processo democrático e as regulamentações legislativas não podem se tornar promessas vazias ou inconsequentes, diante de alegações financeiras do Poder Público.As leis 
existem e precisam ser cumpridas. Assim como o cidadão que descumpre a lei ou que não age, quando a lei determina agir (a exemplo do crime de omissão do socorro, art. 135 do Código Penal (CP)), o Estado deve ser punido quando a sociedade democrática determina que ele faça algo e ele não o faz.

Contudo, observa-se, recorrentemente, que os próprios entes estatais descumprem reiteradamente o que a lei determina. Tal afirmação pode ser confirmada pelos inúmeros mandados de segurança, que visam proteger direito líquido e certo do cidadão, previsto em lei, que são propostos e deferidos (CONSELHO NACIONAL DE JUSTIÇA, 2016). Quantas mais são as leis declaradas inconstitucionais em situações o mais óbvias possíveis. Cite-se, por exemplo, o Estado de Minas Gerais que nomeou servidores públicos sem concurso público em 2007 (BRASIL, 2014), dezenove anos após a CF determinar a indispensabilidade de concursos público (art. 37 da CF). Observe-se também Lei estadual baiana n. ${ }^{\text {o 7.619/2000 }}$ que criou ilegalmente o Município de Luís Eduardo Magalhães (BRASIL, 2007). No SUS, isso ocorre quando o Estado é insuficiente para atender às demandas do cidadão e, quando o Judiciário tenta "corrigir" esse problema, acaba, criando outros problemas, conforme os já enumerados, mas tal situação não desvirtua a relevância da atuação judicial.

Ademais, se as promessas legislativas são grandes demais para o Estado cumprir, deveria ele adequá-las ou reduzi-las. O que não se pode sustentar é que seja criada uma expectativa legítima (posto criada por lei) no cidadão para que, em seguida, seja descumprida. É inerente ao dever de transparência e de moralidade que o Estado deve ter em relação às pessoas deixar claro o que se pode obter e se esperar dos entes governamentais para que não sejam criadas indevidas expectativas.

\section{Consideracões Finais.}

A judicialização da saúde acarreta diversos problemas para a gestão do SUS e, por isso, é alvo de severas críticas. Contudo, não se pode esquecer que a intervenção judicial tem, como raiz, as falhas advindas do próprio sistema de saúde.Se for considerada a óptica da Administração, a judicialização, por certo, é um problema, mas, ao considerarmos a óptica da pessoa, a interferência judicial é, não apenas desejável, mas, em alguns casos, necessária, para que se faça valer os direitos, sobretudo de grupos minoritários ou mediante a interpretação valorativa dos normas jurídicas.Por isso, a judicialização precisa ser mantida, e, a perdurar a 
presente conjuntura de um crescente aumento das ações judiciais, a interferência judicial é algo que tende a se manter.

O que se deve fazer é gerir a judicialização. Assim como o gestor precisa lidar com diversos fatores adversos, como as diversas e distintas demandas populacionais, os interesses políticos e a escassez de recursos, também deve administrar a interferência judicial.E, no presente estudo, já foi possível observar avanços no que tange à relação entre o Judiciário e o Executivo, como foi na consolidação da política de tratamento e combate à AIDS, além de muitos medicamentos terem sido incluídos no fornecimento do SUS diante de propositura maciça de ações judiciais. Por outro lado, o Judiciário tornou-se mais cauteloso ao deferir o acesso a bens de saúde, conforme se observa pela Recomendação n. ${ }^{\circ} 31$ do CNJ e as orientações contidas nas decisões proferidas pelo STF.

Em suma, a judicialização da saúde não é um fenômeno a ser combatido, mas seus efeitos negativos devem ser administrados mediante uma parcerias interinstitucional e posturas dialógicas, sobretudo entre o Executivo e o Judiciário.

\section{Referências.}

AGUIAR, R. A. R..Direito, poder e opressão. 3. ed. São Paulo: Alfa-Omega, 1990.

ARAÚJO, L. M et. al..Judicialização da saúde: uma revisão da literatura. Revista de Enfermagem da UFPI, 2013, abr. - jun.; 2 (2): 49-54. Disponível em:

<http://revistas.ufpi.br/index.php/reufpi/article/view/766/pdf>. Acesso em: 03 abr. 2017.

BANCO MUNDIAL. Governança no Sistema Único de Saúde (SUS) do Brasil: Melhorando a Qualidade do Gasto Público e Gestão de Recursos. 15 fev. 2007. Disponível em: <http://siteresources.worldbank.org/BRAZILINPOREXTN/Resources/38171661185895645304/4044168-1186326902607/19GovernancaSUSport.pdf>. Acesso em: 27 mar. 2017.

BARROSO, L. R..Curso de direito constitucional contemporâneo: os conceitos fundamentais e a construção do novo modelo. São Paulo: Saraiva, 2009.

BOUSQUAT, A.; TANAKA, O. Y.A política de saúde nas páginas da Revista de Saúde Pública. Revista de Saúde Pública, 2016, 50-64. Disponível em:

<http://www.scielo.br/pdf/rsp/v50/pt_0034-8910-rsp-S1518-87872016050000180.pdf>. Acesso em: 03 abr. 2017.

BRASIL. SUPREMO TRIBUNAL FEDERAL. Ação direta de inconstitucionalidade 2.240/BA. Brasília, DF, 09 mai. 2007. Disponível em:

<http://www.stf.jus.br/imprensa/pdf/adi2240.pdf>. Acesso em: 07 mai. 2017. 
.Ação de Descumprimento de Preceito Fundamental (ADPF) $n$. 132. Relator Ministro Ayres Britto. Brasília/DF, 05 de maio de 2011. Disponível em:

$<$ http://redir.stf.jus.br/estfvisualizadorpub/jsp/consultarprocessoeletronico/ConsultarProcesso Eletronico.jsf?seqobjetoincidente $=2598238>$. Acesso em: 10 nov. 2016.

Ação direta de inconstitucionalidade n. ${ }^{\circ}$ 4.876/DF. Brasília, DF, 01 jul. 2014.

Disponível em:

$<$ http://redir.stf.jus.br/paginadorpub/paginador.jsp?docTP=TP\&docID=6272695>. Acesso em: 07 mai. 2017.

Entes federados têm responsabilidade solidária na assistência à saúde, reafirma STF. 13 mar. 2015. Disponível em:

<http://www.stf.jus.br/portal/cms/verNoticiaDetalhe.asp?idConteudo=287303 > . Acesso em: 07 mai. 2015.

Recurso extraordinário com repercussão geral $n .^{\circ} 607.582$ do Rio Grande do Sul. Relatora Ministra Ellen Gracie. Julgado em 13 ago. 2010. Disponível em: $<$ http://redir.stf.jus.br/paginadorpub/paginador.jsp?docTP=AC\&docID=613791>. Acesso em: 06 abr. 2017.

Poder Público deve custear medicamentos e tratamentos de alto custo a portadores de doenças graves, decide o Plenário do STF. Brasília, DF, 17 mar. 2010a. Disponível em: $<$ http://www.stf.jus.br/portal/cms/verNoticiaDetalhe.asp?idConteudo=122125>. Acesso em: 07 mai. 2017.

. Tribunal Regional Federal da $4^{\mathrm{a}}$ Região. Apelação cível n. 2001.71.00.026279-9/RS. Apelante: Ministério Público Federal. Apelada: União Federal. Relator: Juiz Federal Roger Raupp Rios. Porto Alegre, 14 de agosto de 2007a. Disponível em:

<http://www2.trf4.gov.br/trf4/processos/visualizar_documento_gedpro.php?local=trf4\&docu mento $=1838268 \&$ hash=a3e1f66fbd7cfb9f211d00cc73ba3912>. Acesso em: 10 nov. 2016.

CHIEFFI, A. L.; BARATA, R. B.Judicialização da política pública de assistência farmacêutica e eqüidade. Cad. Saúde Pública [online]. 2009, vol.25, n.8, p.1839-1849. Disponível em: <http://www.scielo.br/pdf/csp/v25n8/20.pdf>. Acesso em: 08 mai. 2017.

CONCEIÇÃO, M. C. V.. A greve no serviço público: elementos conceituais e o debate em torno da sua regulamentação. In: Âmbito Jurídico, Rio Grande, XI, n. 52, abr 2008.

Disponível em: <http://www.ambito-

juridico.com.br/site/index.php?n_link=revista_artigos_leitura\&artigo_id=2685>. Acesso em maio 2017.

CONSELHO NACIONAL DE JUSTIÇA. Justiça pesquisa: judicialização da saúde no Brasil. Brasília, 2015. Disponível em:

<http://www.cnj.jus.br/files/conteudo/destaques/arquivo/2015/06/6781486daef02bc6ec8c1e4 91a565006.pdf>. Acesso em: 12 abr. 2017.

100 maiores litigantes. Brasília, DF, mar. 2011. Disponível em:

$\langle$ http://www.cnj.jus.br/images/pesquisas-judiciarias/pesquisa_100_maiores_litigantes.pdf $\rangle$. Acesso em: 07 mai. 2017. 
.Demandas repetitivas e a morosidade na justiça cível brasileira. Julho de 2011a.

Disponível em:

<http://www.cnj.jus.br/files/conteudo/arquivo/2016/03/f7b1f72a0d31cc1724647c9147c4b66b .pdf>. Acesso em: 04 mai. 2017.

Justiça em números 2016, ano-base 2015. Brasília, DF, 2016. Disponível em: <http://www.cnj.jus.br/files/conteudo/arquivo/2016/10/b8f46be3dbbff344931a933579915488 .pdf>. Acesso em: 07 mai. 2017.

Recomendação $n^{\circ} 31$ de 30 de março de 2010. 30 mar. 2010. Disponível em: $<$ http://www.cnj.jus.br///images/atos_normativos/recomendacao/recomendacao_31_30032010 _22102012173049.pdf>. Acesso em: 07 mai. 2017.

COUTO, M. B.; OLIVEIRA, S. P. O Judiciário na Trincheira do Direito Fundamental à Saúde: uma Proposta de Reanálise do Problema da Judicialização das Políticas Públicas à Luz das Teorias do Substancialismo e do Procedimentalismo. RDU, Porto Alegre, Edição Especial, 2016, 182-200. Disponível em:

<https://www.portaldeperiodicos.idp.edu.br/direitopublico/article/view/2786/pdf $>$. Acesso em: 15 mar. 2017.

DEPOIMENTO do Secretário Estadual de Saúde de Minas Gerais, Antônio Jorge de Souza Marques, sobre Judicialização da Saúde (para o curso de Judicialização da Saúde na Atenção Domiciliar). Brasil: Universidade do Estado do Rio de Janeiro, 30 jul. 2013 (vídeo). Vídeo online (7:21 min.). Disponível em: <https://www.youtube.com/watch?v=FQyKmnW0gT8>. Acesso em: 07 mai. 2017.

DINIZ, Debora et. al. Consequências da judicialização das políticas de saúde: custos de medicamentos para as mucopolissacaridoses. Cad. Saúde Pública, Rio de Janeiro, 28(3):479489, mar, 2012. Disponível em: <http://www.scielo.br/pdf/csp/v28n3/08.pdf>. Acesso em: 15 mar. 2017.

DWORKIN, R..O império do direito. São Paulo: Martins Fontes, 2003.

ESTEVAM, Michelle Carolineet. al.Convivendo com transtorno mental: perspectiva de familiares sobre atenção básica. Rev. esc. enferm. USP [online]. 2011, vol.45, n. 3, p. 679686. Disponível em: <http://www.scielo.br/pdf/reeusp/v45n3/v45n3a19.pdf>. Acesso em: 08 mai. 2017.

FANTI, F. Políticas de saúde em juízo: um estudo sobre o município de São Paulo. 2009. 106 f. Dissertação (mestrado em ciência política) - Universidade de São Paulo, São Paulo, SP, 2009. Disponível em: <http://www.teses.usp.br/teses/disponiveis/8/8131/tde-02032010171419/publico/FABIOLA_FANTI.pdf>. Acesso em: 03 mai. 2017.

FERRAZ, O. L. M,; VIEIRA, F. S.. Direito à saúde, recursos escassos e equidade: os riscos da interpretação judicial dominante. Dados [online]. 2009, vol.52, n. 1, p.223-251. Disponível em: <http://www.scielo.br/pdf/dados/v52n1/v52n1a07.pdf>. Acesso em: 08 mai. 2017.

FERREIRA, Camila Duran et al. O Judiciário e as políticas de saúde no Brasil: o caso Aids. São Paulo, 2004. Monografia vencedora do Concurso de Monografias "Prêmio IPEA 40 anos". Disponível em: 
<<http://getinternet.ipea.gov.br/SobreIpea/40anos/estudantes/monografiacamilla.doc>. Acesso em: 06 abr. 2016.

FREITAS FILHO, R. e SANT'ANA, R. N. Direito fundamental à saúde no SUS e a demora no atendimento em cirurgias eletivas. $R D U$, Porto Alegre, Vol. 12, n. ${ }^{\circ} 67,2016,70-102$, janfev 2016. Disponível em:

<https://www.portaldeperiodicos.idp.edu.br/direitopublico/article/view/2576/pdf>. Acesso em: 09 mar. 2017.

LAGUNA, E.; CAMPOS, A.. Existem 300 mil ações sobre direito à saúde, diz ministro. Exame, 7 out. 2016. Disponível em: <http://exame.abril.com.br/brasil/existem-300-mil-acoessobre-direito-a-saude-diz-ministro/>. Acesso em: 12 abr. 2017.

MARQUES, S. B.; DALLARI, S. G. A garantia do direito à assistência farmacêutica no Estado de São Paulo. Revista de Saúde Pública 41 (2): 101-07, 2007.

MATTA, J. L. J.; MARQUES, G. L.. A prestação jurisdicional excessiva como risco ao princípio da universalidade do SUS: pela naturalização do diálogo entre o Direito e a Saúde. Revista Jurídica da Presidência, Brasília, v. 16, n. 109, Jun./Set. 2014, p. 421-441.

Disponível em:

<https://revistajuridica.presidencia.gov.br/index.php/saj/article/viewFile/18/9>. Acesso em: 15 mar. 2017.

MESSEDER,N. M. et. al.Mandados judiciais como ferramentas para garantia do acesso a medicamentos no setor público: a experiência do estado do Rio de Janeiro. Cadernos de Saúde Pública 21 (2): 525-34, 2005.

MOREIRA, W. Revisão de literatura e desenvolvimento científico: conceitos e estratégias para confecção. Revista Janus, Lorena-SP, ano 1, n. ${ }^{\circ}$ 1, $2^{\circ}$ semestre de 2004. Disponível em: <https://www.nesc.ufg.br/up/19/o/Revis_o_de_Literatura_e_desenvolvimento_cient_fico.p df $>$. Acesso em: 08 mai. 2017.

OLIVEIRA, M. Justiça autoriza remédio derivado da maconha para menina com epilepsia. G1, Brasília, 3 mar. 2014. Disponível em: <http://g1.globo.com/distritofederal/noticia/2014/04/justica-autoriza-remedio-derivado-da-maconha-para-menina-comepilepsia.html>. Acesso em: 16 mar. 2017.

OLIVEIRA, Maria dos Remédios Mendes et. al.Judicialização da saúde: para onde caminham as produções científicas? Saúde Debate, Rio de Janeiro, v. 39, n. ${ }^{\circ} 105$, p. 525-535, abr. - jun. 2015. Disponível em: <http://www.scielo.br/pdf/sdeb/v39n105/0103-1104-sdeb-39-10500525.pdf>. Acesso em: 03 abr. 2017.

OLIVEIRA, V. E.; NORONHA, L. N. T. Judiciary-Executive relations in policy making: the case of drug distribution in the State of São Paulo. BPSR, 2011, 5 (2), p. 10-38. Disponível em: <http://www.bpsr.org.br/index.php/bpsr/article/download/133/124>. Acesso em: 26 abr. 2017.

PEPE, Vera Lúcia Edais et. al. A judicialização da saúde e os novos desafios da gestão da assistência farmacêutica. Ciência \& Saúde Coletiva, 15(5): 2405-2414, 2010. Disponível em: <http://www.scielo.br/pdf/csc/v15n5/v15n5a15.pdf>. Acessoem: 24 abr. 2017. 
PINHEIRO, P. S. The Rule of Law anda the Underprivileged in Latin America: Introduction. In: MÉNDEZ, Juan E.; O’DONNEL, Guillermo; PINHEIRO, Paulo Sérgio (orgs.). The (Un)Rule of Law and Underprivileged in Latin America. Notre Dame, Indiana: University of Notre Dame Press, 1999.

RIBEIRO, D. S. O direito à saúde em tempos neoliberais: a judicialização da saúde como estratégia para a garantia de direitos? 2014. 169 f. Dissertação (pós-graduação em serviço social) - Universidade Federal de Juiz de Fora, Juiz de Fora, MG, 2014. Disponível em: <http://www.ufjf.br/ppgservicosocial/files/2014/01/danielle_ribeiro.pdf>. Acesso em: 06 mai. 2017.

SAÚDE pública no Brasil ainda sofre com recursos insuficientes. Brasília: Câmara dos Deputados, 8 jan. 2015. Disponível em:

$<$ http://www2.camara.leg.br/camaranoticias/noticias/SAUDE/480185-SAUDE-PUBLICANO-BRASIL-AINDA-SOFRE-COM-RECURSOS-INSUFICIENTES.html>. Acesso em: 13 abr. 2016.

SANTOS, L. Caderno didático fornecido ao curso à distância de judicialização da saúde em atenção domiciliar, promovido pela Universidade do Estado do Rio de Janeiro - UERJ, abr. 2017.

SCHEFFER, Mário et. al. (coord.) O remédio via justiça: um estudo sobre o acesso a novos medicamentos e exames em HIV/Aids no Brasil por meio de ações judiciais. Série Legislação, n 3: 24-38. Brasília: Ministério da Saúde, 2005. Disponível em:

<http://bvsms.saude.gov.br/bvs/publicacoes/medic_justica01.pdf〉. Acesso em: 08 mai. 2017.

SCOCUGLIA, Livia. Morosidade da Justiça só serve a quem não tem razão, diz Renato Nalini. Conjur, 24 nov. 2014. Disponível em: <http://www.conjur.com.br/2014-nov24/morosidade-serve-quem-nao-razao-renato-nalini>. Acesso em: 04 mai. 2017.

VENTURA, Miriam et. al. Judicialização da saúde, acesso à justiça e efetividade do direito à saúde. Revista de Saúde Coletiva, Rio de Janeiro, 20 [1]: 77-100, 2010. Disponível em: <http://www.scielo.br/pdf/physis/v20n1/a06v20n1.pdf>. Acesso em: 15 mar. 2017.

VIEIRA, F. S.; ZUCCHI, P. Distorções causadas pelas ações judiciais à política de medicamentos no Brasil. Rev. Saúde Pública [online]. 2007, vol.41, n.2, pp.214-222. Disponível em: 〈http://www.scielo.br/pdf/rsp/v41n2/5587.pdf>. Acesso em: 08 mai. 2017.

VIEIRA, F. S. Ações judiciais e direito à saúde: reflexão sobre a observância aos princípios do SUS. Rev. Saúde Pública, 2008, 42 (2): 365-9. Disponível em:

<http://www.scielo.br/pdf/rsp/v42n2/6847.pdf>. Acesso em: 08 mai. 2017.

WANG, Daniel Wei L. et. al. Os impactos da judicialização da saúde no município de São Paulo: gasto público e organização federativa. Rev. Adm. Pública, Rio de Janeiro, 48 (5): 1191-1206, set./ out. 2014. Disponível em: 〈http://www.scielo.br/pdf/rap/v48n5/06.pdf>. Acesso em: 25 abr. 2017.

WALDRON, J. A essência da oposição ao judicial review. In: BIGONHA, A. C. A.; MOREIRA, L. (Orgs.). Legitimidade da Jurisdição Constitucional.Rio de Janeiro: Lumen Júris. 2010. 
WOLKMER, A. C.Ideologia, Estado e Direito. São Paulo: RT, 2003. 